\title{
Genç Erişkinlerde Videonistagmografi ile Yapılan Okülomotor Test Sonuçlarının İncelenmesi
}

Evaluation of Oculomotor Tests Findings Using Videonystagmography in Young Adults

\author{
Bilgehan TEKiN DAL ${ }^{1}$, Nebil GÖKSU ${ }^{2}$, Çağıl GÖKDOĞAN ${ }^{3}$, Yusuf Kemal \\ KEMALOĞLU ${ }^{4}$ \\ 1 Arş. Gör., Gazi Üniversitesi, Sağlık Bilimleri Fakültesi, Odyoloji Bölümü, Ankara, Türkiye \\ ${ }_{2}$ Prof. Dr., Gazi Üniversitesi, Tıp Fakültesi, Kulak Burun Boğaz Hastalıkları Anabilim Dalı, Ankara, Türkiye \\ ${ }^{3}$ Doç. Dr., Muğla Sıtkı Koçman Üniversitesi, Tıp Fakültesi, Kulak Burun Boğaz Hastalıkları Anabilim Dalı, Muğla, Türkiye \\ ${ }^{4}$ Prof. Dr., Gazi Üniversitesi, Tıp Fakültesi, Kulak Burun Boğaz Hastalıkları Anabilim Dalı, Ankara, Türkiye
}

\section{öz}

\begin{abstract}
Amaç: Videonistagmografi (VNG), vestibüler sistemi değerlendiren önemli bir laboratuvar testidir. VNG; okülomotor testler, gaze stabilizasyon testleri, pozisyonel testler ve kalorik alt testlerinden oluşur. Okülomotor testler (sakkad, pursuit ve optokinetik testler), santral vestibüler sistemi değerlendirir. Bu çalışma, genç erişkin bireylerin videonistagmografi (VNG) cihazı ile yapılan okülomotor test sonuçlarını incelenmesi ve okülomotor alt testlerine (pursuit testi, sakkadik testi ve optokinetik nistagmus testi) ait değerlendirme parametrelerinin normatif değerlerinin belirlenmesi amacıyla yapılmıştır. Gereç ve Yöntem: Bu makalede, 18-35 yaş aralığında, saf ses odyometri testi sonuçlarına göre normal sınırlarda işitme eşiklerine sahip, kalorik test sonuçları ile Vertigo engellik ölçeğine (VEÖ) göre vestibüler problemi olmayan, 25 genç erişkin bireyin (12 erkek 13 kadın) okülomotor değerlendirme sonuçları analiz edilmiştir. Sonuçlar: Çalışmada, VNG okülomotor testlerinin sağlıklı genç erişkinlere ait normatif değerleri sunulmuştur. Tartışma: Klinisyenlerin videonistagmografik okülomotor testlerin sonuçlarını yorumlamada kullanabilecekleri referans değerler belirlenmiştir.
\end{abstract}

Anahtar Sözcükler: Baş dönmesi; Göz hareketi ölçümleri; Genç erişkin

\section{ABSTRACT}

Purpose: Videonystagmography is one of the important laboratory test which evaluates vestibular system. VNG consists of several subtests such as oculomotor tests, gaze stabilization tests, positional tests and caloric test. Oculomotor tests (saccade, tracking and optokinetic tests) assess central vestibular system. The aim of this study was to examine the results of oculomotor test and to establish normative data for oculomotor tests (saccade, tracking and optokinetic tests) parameters in young adults by using VNG. Material and Methods: In this paper, the results of oculomotor tests were evaluated in 25 young adults (12 males and 13 females) between 18-25 years of age with normal hearing thresholds as a result of pure tone audiometry test results and without vestibular problems according to caloric test result with vertigo handicap questionnaire (VHQ). Results: The present study, a data base of normal values for VNG oculomotor tests in healthy young adults. Discussions: Establishing normative data can provide references ranges using by clinicians to interpret results of videonistagmografic oculomotor tests.

Keywords: Dizziness; Eye movement measurements; Young adults 
Denge, statik ve dinamik pozisyonlarda vücudun yerçekimi merkezi değişikliklerine gösterdiği uyuma denir (Pollock, Durward, Rowe ve ark., 2000). Bu uyum, denge sisteminin temel iki fonksiyonu ile sağlanır. Bunlardan ilki, baş hareketleri sırasında görme alanını sabit tutmak, ikincisi ise vücut ağırlık merkezini destek yüzeyi içerisinde tutmaktır. Denge sisteminin bu temel iki fonksiyonu vestibüler, vizüel ve proprioseptif sistemler arasındaki entegrasyon ve üç sistemin reseptörleri tarafından alınan bilgilerin merkezi sinir sisteminde işlemlenmesi ve organize edilmesiyle sağlanır (Peterka, 2002; Ardıç, 2019). Baş hareketliyken görme alanını sabit tutmak kişiye net ve temiz bir görüş sağlar. Bundan dolayı doğal baş hareketleri sırasında kompansatuvar göz hareketleri açığa çıkar. Bu kompansatuvar göz hareketleri refleksiftir ve vestibulo-oküler refleks (VOR) olarak bilinir.

Kompansatuvar göz hareketleri 6 sistem tarafından kontrol edilir. Fiksasyon sistemi; bir cisme bakarken görüntünün foveada sabit tutarak görme netliği sağlayan düz bakışı (gaze) açığa çıkaran sistemdir. Vestibüler sistem; küçük baş hareketleri sırasında cismin görüntüsünü foveada sabit tutar. Sakkadik sistem; istemli ve en hızlı göz hareketi olan sakkadik göz hareketini kontrol eder. Görme alanının dışında kalan görüntüyü foveaya düşürmek için yapılan hızlı ve istemli bir göz hareketi bir sakkad olarak adlandırılır ve görsel, işitsel gibi periferik uyarılar tarafından açığa çıkar. Pursuit sistem; yavaş hareket eden cismin görüntüsünün foveada kalması için istemli göz hareketlerini kontrol ederek cisim ile gözün aynı hızda hareket etmesini sağlar. Optokinetik sistem; ise sürekli yapılan baş hareketlerine bir süre sonra vestibüler sistem uyum sağlayamaz ve VOR kaybolur. Bu durumu kompanse etmek için sistem, optokinetik göz hareketlerini açığa çıkararak sürekli baş hareketleri sırasında görüntünün foveada kalmasını sağlar. Verjans sistem; aynı anda görüntüyü her iki foveada tutmak için yapılan zıt yönlü göz hareketlerini sağlar (Krauzlis, 2008).

Videonistagmografi (VNG), kızılötesi ışıklarla gözü aydınlatarak, göz hareketlerini "video goggles" denilen kameralı gözlüklerle kaydeden, analizini yapan yüksek teknoloji bir laboratuvar testidir. VNG, denge ve baş dönmesine neden olabilecek vestibüler bir hastalığın olup olmadığını belirlemede kullanılır. Ancak vestibüler sistemin tümünü değerlendiremez yalnızca VOR hakkında bilgi verir. Bununla birlikte, vestibulo-oküler yoldaki patolojinin periferik veya santral ayırımını yapmada, periferal ise tek taraflı veya bilateral patolojiyi ayırt etmede, patolojinin progresyonu ve iyileşmesi hakkında da bilgi veren non-invaziz, uygulaması kolay, ucuz ve güvenilir bir testtir. VNG testi sakkad, pursuit, optokinetik testleri içeren "okülomotor testler", spontan/gaze nistagmus ve statik pozisyon testlerini içeren "gaze stabilizasyon testleri", Dix-hallpike, roll ve fistula testi gibi "spesifik tanı testleri" ve "kalorik test" alt testlerinden oluşur (Mekki, 2014). Okülomotor testler santral vestibüler sistemin değerlendirilmesinde kullanılan VNG alt testlerindendir.

Baş dönmesi ve denge bozukluğu şikâyeti olan hastaların değerlendirilmesinde kullanılan, videonistagmografi test bataryası içinde yer alan okülomotor testlerinden elde edilen sonuçlara göre normal ve patolojik durumların ayırımının doğru bir şekilde yapılabilmesi için değerlendirme parametrelerine ait normatif verilerinin belirlenmesi önemlidir. Literatür incelenildiğinde, okülomotor test sonuçlarının normatif değerlerinin incelendiği sınırlı sayıda araştırma olduğu görülmektedir (Kang ve Kim, 2015; Wuyts ve Boniver, 2008; Stappen, 2000). Yine literatür incelenildiğinde ülkemizde yapılan benzer bir çalışmaya rastlanılmamıştır.

$\mathrm{Bu}$ çalışmada, videonistagmografik okülomotor testlerin sonuçlarını yorumlamada kullanılmak üzere klinisyenlere yardımcı olacak, sağlıklı genç erişkinlere ait referans değerleri ortaya koymak amaçlanmıştır.

\section{GEREÇ VE YÖNTEM}

Bu çalışma için Gazi Üniversitesi Etik Kurulu'ndan izin alınmıştır. Bireyler, çalışmanın uygulanışı ve amacı ile ilgili sözlü olarak bilgilendirilmiş, çalışmaya katılmayı kabul eden tüm bireylere bilgilendirilmiş, gönüllü onam formları imzalatılmıştır. Çalışmanın tüm prosedürleri, Helsinki Deklarasyonu Prensiplerine uygun şekilde yapılmıştır.

Çalışmada 18-35 yaş arası, normal işitmesi olan, vestibüler patolojisi olmayan, 25 genç erişkin bireyin (12 erkek, 13 kadın) videonistagmografik okülomotor test sonuçları incelenmiştir. Çalışmaya dahil edilme kriterleri; normal otoskopik muayene bulguları olma, saf ses odyometri test sonuçlarına göre normal işitme eşiklerine sahip olma, kalorik test sonuçları normal sınırlarda olma ve vertigo engellilik anketi sonuçlarına göre vestibüler problemi bulunmama olarak belirlenmiştir. Otolojik cerrahi geçirenler, nörolojik hastalığı olanlar, görme bozukluğu olanlar, ototoksik ilaç kullananlar, kafa travması hikayesi olanlar çalışmaya dahil edilmemiştir. Çalışmaya alınacak birey sayısı, literatürde objektif vestibüler testlerin yaşa göre normatif değerlerini yayınlayan araştırmalar ve çalışmamızdaki yaş aralığı dikkate alınarak 
belirlenmiştir (Trueblood ve ark., 2018; Khan ve ark., 2014; Janky ve Shepard, 2009). Göz hareketleri, Video ENG Micromedical Technologies INC cihazı ile kaydedilmiştir. Kayıtlar, VNG testi için düzenlenmiş odada uygulanmıştır.

Okülomotor testlerin ilk alt testi olan sakkad testinde; katılımcılardan horizontal düzlemde, rastgele 2-3 sn'lik aralıklarla 30 sıçrayış yapan hedefi başlarını hareket ettirmeden gözleriyle takip etmeleri istenmiştir. Her göz (sağ göz ve sol göz) için sakkadik hareketin latans değerleri ve doğruluğu analiz edilmiştir. Smooth Pursuit testinde, katılımcılardan horizontal düzlemde sarkaç gibi sağa sola kayan ve hareket hızı giderek artan hedefi, başlarını hareket ettirmeden gözleri ile takip etmeleri istenmiştir. Her göz için (sağ ve sol) tüm frekanslarda $(0.1 \mathrm{~Hz}, 0.2 \mathrm{~Hz}$ ve $0,4 \mathrm{~Hz}$ ) elde edilen kazanç değerleri analiz edilmiştir. Optokinetik testte, testin ilk yarısında soldan sağa doğru ikinci yarısında ise sağdan sola doğru art arda sabit hızla akan (20 derece/sn) görsel hedeflerden orta hatta yer alanları, başını hareket ettirmeden, gözleri ile sayması istenmiştir. Uygulanan testin sonucunda, görme alanının temporalinden nazaline (TN) doğru ve nazalinden temporaline (NT) doğru elde edilen fizyolojik nistagmusların, her göz için ayrı olarak kazanç değerleri belirlenmiştir.

İstatistiksel analizler, SPSS-WINDOWS'15.0 paket 34 programda yapılmıştır. Değerlendirme parametrelerinden elde edilen sayısal verilerin, normal dağılım gösterip göstermediği görsel (histogram ve olasılık grafikleri) ve analitik
(Kolmogorov-Smirnov/Shapiro - Wilk testler) yöntemler ile yapılmıştır. Yapılan analizlerden elde edilen bulgulara göre sayısal verilen normal dağılım göstermediği bulunmuştur. Gözler arasındaki gibi bağımlı grup verileri, NonParametrik testlerden Wilcoxon testi ile karşılaştırılmıştır. Yanılma düzeyi 0.05 seçilmiş, bu değerden küçük p değeri için anlamlı farklıığın olduğu değerlendirilmesi yapılmıştır. Tanımlayıcı istatistiklerin sunumunda ortalama \pm standart sapma (ort $\pm \mathrm{ss}$ ), mininum ( $\mathrm{min}$ ) ve maksimum (maks) gösterimi kullanılmıştır (Hayran, 2011).

\section{SONUÇLAR}

Çalışmada işitme kaybı ve vestibüler problemi olmayan, 18-35 yaş aralığı (ortalama $25,40 \pm 4.55$ yaş) 25 genç erişkin bireyin videonistagmografik okülomotor test sonuçları analiz edilmiştir. Bireylerin 12 (\%48) 'si erkek, 13 (\%52)'si kadındı ve erkek ile kadın bireyler sayıları açısından istatistiksel anlamlı fark bulunmadı.

Sağ göz ve sol göz için sakkad testi ortalama latans değerleri, $0,1 \mathrm{~Hz}, 0,2 \mathrm{~Hz}$ ve $0,4 \mathrm{~Hz}$ frekanslarda pursuit testi ortalama kazanç değerleri ile optokinetik testi ortalama kazanç değerleri ait belirlenmiş ve Tablo 1'de sunulmuştur.

Sakkad testinde doğruluk parametresi için \%77'nin altında elde edilen değerler hipometrik, \%137'nin üstünde elde edilen değerler hipermetrik sakkad olarak kabul edilmiştir. Sağ göz abdüksiyonda 1 (\%4), addüksiyonda 4(\%16), sol göz abdüksiyonda ise 1 (\%4) hipermetrik sakkad olduğu tespit edilmiştir.

Wilcoxon testi ile sağ göz ve sol göz için değerlendirme parametrelerine ait değerler arasında istatistiksel açıdan anlamlı bir fark olmadığı belirlenmiştir ( $p>0.05)$.

Tablo 1. Genç yetişkin bireylere ait videonistagmografik okülomotor test değerlendirme verileri

\begin{tabular}{|c|c|c|c|}
\hline \multicolumn{2}{|c|}{ Okülomotor Testler } & $\begin{array}{c}\text { Sağ göz } \\
\text { (ortıss) (min-maks) }\end{array}$ & $\begin{array}{c}\text { Sol göz } \\
\text { (ort } \pm s s)(m i n-m a k s)\end{array}$ \\
\hline \multicolumn{4}{|c|}{ Sakkad Testi } \\
\hline \multirow[t]{2}{*}{ Latans } & $A b d$ & $123,32 \pm 27,14(67-171)$ & $131,36 \pm 24,77(72-178)$ \\
\hline & Add & $122,68 \pm 25,34(67-158)$ & $130,36 \pm 29,39(82-179)$ \\
\hline \multicolumn{4}{|c|}{ Pursuit Testi } \\
\hline \multirow[t]{3}{*}{ Kazanç } & $0,1 \mathrm{~Hz}$ & $0,89 \pm 0,16$ & $0,87 \pm 0,17$ \\
\hline & $0,2 \mathrm{~Hz}$ & $0,94 \pm 0,12$ & $0,91 \pm 0,12$ \\
\hline & $0,4 \mathrm{~Hz}$ & $0,92 \pm 0,13$ & $0,92 \pm 0,12$ \\
\hline \multicolumn{4}{|c|}{ Optokinetik Test } \\
\hline \multirow[t]{2}{*}{ Kazanç } & $T N$ & $0,63 \pm 0,36(0-1,13)$ & $0,70 \pm 0,31(0-1,21)$ \\
\hline & $N T$ & $0,74 \pm 0,28(0-1,06)$ & $0,60 \pm 0,35(0-1,18)$ \\
\hline
\end{tabular}




\section{TARTIŞMA}

Fonksiyonel göz hareketlerinin incelenmesi, vestibüler sistemin bütünlüğünü hakkında bilgi sahibi olmamızı sağlar. Göz hareket sistemini değerlendirmek, periferik vestibüler sistem ile ilgili doğrudan bilgi vermese de serebellum ve beyin sapında bulunan santral vestibüler sistem ile bunların bağlantı yolları hakkında bilgi sahibi olmamızı sağlar. Ek olarak, okülomotor sistemin kapsamlı değerlendirilmesi, ayırıcı tanıda klinisyene değerli bilgiler verir (McCaslin, 2019).

Bu çalışmada, videonistagmografi cihazı ile yapılan okülomotor test sonuçlarının, normal ve patolojik durumların ayırımında doğru bir şekilde kullanılabilmesi için, sağlıklı genç yetişkin bireylere ait referans değerlerler belirlenmiştir.

Sakkad testinde, gözü bir hedeften başka bir hedefe doğru hızla hareket ettirme ve hedefe gözü yeniden sabitleme (refiksasyon) yeteneği değerlendirilir (Mekki, 2014). Sakkadik göz hareketi isteğe bağlı olarak veya istemsiz olarak ortaya çıkabilir (Premachandra, 2013). Sakkad testinin değerlendirme parametrelerinden olan sakkadik latans, görsel uyaran ile sakkadik göz hareketi arasında geçen zaman olarak tanımlanmaktadır. Latansın uzaması; frontal korteks, frontoparietal korteks veya bazal gangliyonlardaki santral bir lezyonun göstergesidir. Unilateral latans uzaması bilateral latans uzamasına göre klinik açıdan çok daha önemlidir (Mekki, 2014). Konuyla ilgili yapılan bir çalışmada, 20-29 yaş arası 16 yetişkin bireyin, rastgele sakkadik latans ortanca değerinin 117 msn, 30-39 yaş arası 15 yetişkin bireyin latans ortanca değerinin ise $127 \mathrm{msn}$ olduğu bildirilmiştir (Gonçalves ve Scharlach, 2016). Yılmaz, Söylemez, İla ve arkadaşları (2020) tarafından yapılan çalışmada, yaş aralığı 18- 45 olan sağlıkı yetişkin bireylere ait ortalama sakkadik latans değerinin 124,25 $\pm 22,58$ msn olduğu bildirilmiştir. Kang ve Kim (2015), 40 yaş altı genç yetişkinlerin sakkadik latans normatif değerlerinin, sol göz abdüksiyonunda 198,0 msn, sağ göz abdüksiyonunda 176,3 msn, sol göz addüksiyonunda $175.1 \mathrm{msn}$ ve sağ göz addüksiyonunda 188,9 msn olduğunu belirlemişlerdir. Çalışmamızda elde ettiğimiz sakkadik latans değerlerinin, literatürle uyumlu bulunmuştur.

Sakkadik test sonuçlarını değerlendirmede kullanılan bir diğer değerlendirme parametresi ise doğruluktur. Bu değerlendirmede, görsel hedefi gözün ne kadar doğru takip ettiği belirlenir. Görsel hedefi gözler ile doğru takip edememeye sakkadik dismetri denir. Hipometrik sakkad ve hipermetrik sakkad olmak üzere iki tip sakkadik dismetri görülür. Göz hedefin önemli derecede arkasında kalırsa hipometrik sakkad, önemli derecede önüne geçerse hipermetrik sakkad denir. Bununla birlikte hipermetrik sakkadlar her zaman patoloji göstergesi değildir. (McCaslin, 2019). Sağlıklı bireylerde de geçici ve 10 dereceden az hipermetrik sakkadlar görülebilir. Hipermetrik sakkadlar sık olduğunda (zamanın en az $\% 50$ 'si) ve derecesi fazla olduğunda (\%2 dereceden fazla) anormal olarak yorumlanır. Serebellar lezyonlarda, görme alanı bozukluklarında ve internükleer oftalmoplejide görülür (Hain, 2019; Termsarasab ve ark., 2015). Hipometrik sakkadlar ise hareketin başlangıcında çok küçüktür ve hedefe doğru düzeltici sakkadlar ile devam eder. Sağlıklı kişilerde de görülebildiği için hipermetrik sakkadlar gibi hemen patoloji göstergesi olarak kabul edilmez. Hastanın kataraktının olması veya test sırasında gözlük takamaması gibi nedenlerden dolayı hipometrik sakkadların ortaya çıkabileceği unutulmamalıdır. Ancak sürekli ve önemli oranda (\%50'nin üstünde) görülen hipometrik sakkadlar, Parkinson hastalığı veya progresif supranükleer palsi gibi bazal gangliyon bozuklukları ve Tay-Sachs hastalığı gibi dejeneratif sinir sistemi hastalıklarını düşündürür (Hain, 2019; Rucker, Shapiro, Han ve ark., 2004). Çalışmamızda 25 sağlıklı bireye ait toplam 50 gözün sakkadik test sonuçları değerlendirilmiş ve 2 gözde abdüksiyonda, 4 gözde ise addüksiyonda hipermetrik sakkad tespit edilmiştir. Elde ettiğimiz bu bulgunun literatürde belirtilen, sağıkı bireylerde de hipometrik ve hipermetrik sakkadlar görülebileceği (Hain, 2019; McCaslin 2019) bilgisiyle uyumlu olduğu görülmektedir.

Pursuit testi, oküler takip testi olarak da bilinir (Perepa, 2017; Bhansali ve Honrubia,1999). Pursuit testinde morfolojik değerlendirmenin yanı sıra kullanılan bir diğer değerlendirme parametresi de kazançtır. Kazanç, göz hareketi hızının görsel hedef hareketinin hızına oranıdır (göz hızı/hedef hız). Kazanç değeri, 30 derece/sn ve $0.3 \mathrm{~Hz}$ 'e kadar olan hızlar için 1'e yakın olmalıdır ve $>0.8$ norm olarak kabul edilir. Elde edilen değer 0,2 ila 0,8 arasında ise azalmış kazanç denir ve genellikle dikkat eksikliği, azalmış görme keskinliği ve santral sinir sistemini etkileyen ilaç veya alkol alımından kaynaklanmaktadır. Değer 0.2'nin altında ise eksik kazanç (absent gain) denir ve santral sinir sistemi bozukluğunun göstergesidir (Premachandra, 2013). Literatür incelendiğinde, 18-43 yaş aralığındaki 23 erişkin bireyin pursuit testi ortalama kazanç değerlerinin $0.1 \mathrm{~Hz}$ 'de $0,97 \pm 0.06,0.2 \mathrm{~Hz}$ 'de $0,92 \pm 0.08$ ve $0,4 \mathrm{~Hz}$ 'de $0.87 \pm 0.11$ olduğu görülmektedir 
(Moschner ve Baloh, 1994). Seferlis ve arkadaşları (2015) tarafından yapılan çalışmada 0.6 Hz'de kazanç değerinin 18-30 yaş aralığında, sola doğru $88,92 \pm 12,82$, sağa doğru $90,24 \pm 11,75$ olduğu, 30-39 yaş aralığında ise sola doğru $88,18 \pm 12,9$ ve sağa doru $91,12 \pm 9,88$ olduğu belirtilmiştir. Çalışmamızda elde ettiğimiz bulgular literatürde vurgulanan bu bulgular ile uyumlu elde edilmiştir.

Optokinetik test, optokinetik nistagmus'u (OKN) değerlendiren okülomotor alt testlerden bir diğeridir. OKN, görsel alanın hareketine yanıt olarak ortaya çıkan refleksif göz hareketidir. Uyaran yönünde yavaş bir faz ve bunu takiben ters yönde ortaya çıkan düzeltici, hızlı faz olmak üzere iki farklı hızda göz hareketini içerir. OKN ile pursuit göz hareketleri birbiriyle yakın ilişkilidir. Her ikisi de görsel takip içerir. Ancak OKN, pursuit 'ten farklı olarak görsel bir hedefi değil görsel bir alanı izleme sonucu ortaya çıkar. Ek olarak, pursuit sistem foveal stimulasyon ile uyarılırken, optokinetik sistem retinanın tam alan periferal stimülasyonu ile uyarılır. OKN'nin amacı, baş hareket halindeyken tüm görme alanını stabilize etmektir. Pursuit göz hareketinin amacı ise fovea üzerindeki tek bir hedefin yerini korumaktır. Uzun süreli baş rotasyonunda, vestibüler sistem uyarı göndermeyi bırakır ve bu noktada optokinetik sistem devreye girer. Vestibüler sistemin sıvı hareketi, 10 ila 15 sn 'den uzun süren baş rotasyonlarında kupula stimülasyonunu devam ettiremez. Görsel (optokinetik) inputlar, vestibüler nukleuslara ulaşır ve sönmekte olan labirent sinyalini takviye eder. OKN, aydınlık ortamda, kişinin sürekli kendi etrafında dönmesi (rotasyonu) sonucu oluşur. Ancak klinik ortamda, hasta sabit otururken, hastanın etrafında dönen görsel bir alan ile ortaya çıkarılır. Periferik vestibüler stimülasyon olmamasına rağmen, hasta dairesel hareket (döndüğünü) hisseder. İnsanlarda OKN refleksini uyarmak için, görsel alanın 60 saniye boyunca, saniyede 60 derecede hızda döndürülmesi gerekir. Test sırasında uyaran olarak genellikle hareketli çizgiler veya nesneler kullanılır (Eggers, 2020; Leigh ve Zee, 2015). Optokinetik test sonucunda orta çıkan göz hareketini değerlendirmede kullanılan parametrelerden biri kazançtır. Kazanç, göz hareketi hızının, görsel uyaran hızına oranı ile elde edilir. Beyin sapı ve serebral korteksin oküler motor yollarını etkileyen lezyonlarda, OKN anormallikleri not edilir (Perepa, 2017). Stappen (2020) tarafından yapılan çalışmayı incelediğimizde, yaş ortalaması 44,6 yıl olan 40 sağlıklı yetişkin bireyin optokinetik test ortalama kazanç değerinin $0,84 \pm 0,16$ olduğu ve bu değerin çalışmamızda elde ettiğimiz değerle uyumlu olduğu görülmektedir.

Bir hastanın videonistagmografik okülomotor test sonuçlarını doğru bir şekilde yorumlamak için güncel, güvenilir normatif verilerin bilinmesi önemlidir. Çalışmamızda, videonistagmografi cihazıyla yapılan okülomotor test sonuçlarının yorumlanmasında kullanılabilecek sağlıklı genç erişkin bireylere ait referans değerler belirlenmiştir.

Bu çalışmanın en önemli kısıtlılığı, sadece 18-35 yaş aralığındaki sağlıklı erişkinlerin okülomotor test sonuçları incelenmiştir. Gelecekte farklı yaş grupları için cinsiyete özgü normatif değerlerin belirleneceği çalışmaların, klinik uygulamalar için faydalı olacağı düşünülmektedir.

\section{Araştırmacıların Katkı Oranı}

Bilgehan TEKIN DAL: Araştırmanın planlanması, kaynak tarama, veri toplama, analiz etme ve makalenin yazımı. Nebil GÖKSÜ: Araştırmanın denetleme ve danışmalığını yapma. Çağıl GÖKDOĞAN: Kaynak tarama, sorumluluk alma.

Yusuf Kemal Kemaloğlu: Araştırmanın planlanması ve eleştirel inceleme yapma.

\section{Çıkar Çatışması Beyanı}

Bu çalışmada yer alan yazarların herhangi bir çıkar çatışması bulunmamaktadır.

\section{Destek/Teşekkür}

Çalışma için hiçbir kurum ya da kişiden finansal destek alınmamıştır.

\section{Kaynaklar}

Ardıç, F. N. (2019). Denge sisteminin işleyişi. F. N. Ardıç (Ed.), Vertigo, (2. Baskı) içinde (ss. 1-20). İzmir: Güven Kitabevi.

Bhansali, S. A., \& Honrubia, V. (1999). Current status of electronystagmography testing. Otolaryngol Head Neck Surg, 120, 419-426. https://doi.org/10.1016/S0194$5998 \% 2899 \% 2970286-X$

Eggers, S. D. Z. (2020). Practical anatomy and physiology of the ocular motor system. In G. P. Jacobson, N. T. Shepard, K. Barin, K. Janky, \& D. L. McCaslin (Eds), Balance Function Assessment and Management, (Third Edition, pp. 43-68). San Diego, CA: Plural Publishing Inc.

Gonçalves, V. P., \& Scharlach, R. C. (2016). Oculomotor evaluation in adults: A study of the effect of age and visual alterations. Audiol Commun Res, 21, e1704-e1710. http://dx.doi.org/10.1590/2317-6431-2016-1704

Hain, T. C. (2019). Disorders of saccadic accuracy. Retrieved from the Web June 01, 2020. https://www.dizziness-andbalance.com/practice/saccades/saccadic\%20dysmetria.html

Hayran, M. (2011). Sağlık araştırmaları için temel istatistik. Ankara: Omega yayınları. 
Janky, K., \& Shepard, N. (2009). Vestibular evoked myogenic potential (VEMP) testing: normative threshold response curves and effects of age. J Am Acad Audiol, 20(8), 514-522. https://doi.org/10.3766/jaaa.20.8.6.

Kang, S., \& Kim, U. S. (2015). Normative data of videonystagmography in young healthy adults under 40 years old. Korean J Ophthalmol, 29(2), 126-130. https://doi.org/10.3341/kjo.2015.29.2.126

Khan, F. K., Balraj, A., \& Lepcha, A. (2014). Normative data for vestibular evoked myogenic potential in different age groups among a heterogeneous Indian population. Indian Indian J Otolaryngol Head Neck Surg, 66(2), 149-154. https://doi.org/10.1007/s12070-013-0685-z.

Krauzlis, R. J. (2008). Eye movements. In L. Squire, D. Berg, F. Bloom, S. Du Lac, A. Ghosh, \& N. Spitzer (Eds), Fundamental Neuroscience, (Third Edition, pp. 775-794). Burlington, MA: Academic Press.

Leigh, R. J., \& Zee, D. S. (2015). The vestibular-optokinetic system. In R. J. Leigh, \& D. S. Zee (Eds.), The Neurology of Eye Movements, (Fifth Edition pp. 55168). New York: Oxford University.

McCaslin, D. L. (2019). Eye movement examination. In D. L. McCaslin (Ed.), Electronystagmography and Videonystagmography (ENGNNG), (Second Edition, pp. 87-122). San Diego, CA: Plural Publishing Inc.

Mekki, S. (2014). The role of videonystagmography (VNG) in assessment of dizzy patient. The Egyptian Journal of Otolaryngology, 30(2), 69-69.

Moschner, C., \& Baloh, R. W. (1994). Age-related changes in visual tracking. Journal of Gerontology, 49(5), M235M238. https://doi.org/10.1093/geronj/49.5.M235

Perepa, L. S. (2017). Objective evaluation of patients with vestibular disorders. Global Journal of Otolaryngology, $7(4)$, 555716. https://doi.org/10.19080/GJO.2017.07.555716

Peterka, R. J. (2002). Sensorimotor integration in human postural control. J Neurophysiol, 88(3), 1097-1118. https://doi.org/10.1152/jn.2002.88.3.1097

Pollock, A. S., Durward, B. R., Rowe, P. J., \& Paul, J. P. (2000). What is balance? Clin Rehabil, 14(4), 402-406. https://doi.org/10.1191/0269215500cr342oa

Premachandra, P. (2013). Special investigations used in the assessment of the dizzy patient. The Otorhinolaryngologist, 6(1), 6-14.

Rucker, J. C., Shapiro, B. E., Han, Y. H., Kumar, A. N., Garbutt, S., \& Leigh, R. J. (2004). Neuroophthalmology of late-onset Tay-Sachs disease. Neurology, 63(10), 1918-1926. https://doi.org/10.1212/01.WNL.0000144275.76658.F 4

Seferlis, F., Chimona, T. S., Papadakis, C. E., Bizakis, J., Triaridis, S., \& Skoulakis, C. (2015). Age related changes in ocular motor testing in healthy subjects. $J$ Vestib Res, 25(2), 57-66. https://doi.org/10.3233/VES150548

Stappen, A. V. D. (2000). Computerized electronystagmography: Normative data revisited. Acta Oto-Laryngol, 120(6), 724-730. https://doi.org/10.1080/000164800750000243

Termsarasab, P., Thammongkolchai, T., Rucker, J. C., \& Frucht, S. J. (2015). The diagnostic value of saccades in movement disorder patients: a practical guide and review. J Clin Mov Disord, 2(1), 1-10. https://doi.org/10.1186/s40734-015-0025-4

Trueblood, P. R., Rivera, M., Lopez, C., Bentley, C., \& Wubenhorst, N. (2018). Age-based normative data for a computerized dynamic posturography system that uses a virtual visual surround environment. Acta Otolaryngol, 138(7), 597-602. https://doi.org/10.1080/00016489.2018.1429653

Wuyts, F., \& Boniver, R. (2008). Normative data in ENG and VNG. B ENT, 3 (Suppl. 8), 45-48.

Yılmaz, N., Söylemez, E., İla, K., Söylemez, T., \& Ertuğrul, S. (2020). Yaşlanmanın okülomotor fonksiyonlara etkisi. Kulak Burun Boğaz ve Baş Boyun Cerrahisi Dergisi, 28(1), 16-21. https://doi.org/10.24179/kbbbbc.2019-72290 